\title{
Promotoras (community health workers) improve heart health among Latinos in rural and urban settings
}

\author{
Katrina Kubicek ${ }^{1,4^{*}}$, Marisela Robles ${ }^{1}$, Lourdes Baezconde-Garbanati ${ }^{2}$, Melinda Cordero-Barazaga ${ }^{3}$, \\ Michele D Kipke ${ }^{1,2,4}$
}

From 7th Annual Conference on the Science of Dissemination and Implementation in Health North Bethesda, MD, USA. 8-9 December 2014

The project was aimed at reducing cardiovascular health disparities by implementing an evidence-based curriculum (Su Corazón Su Vida) delivered by promotoras in underserved communities. This 11-session intervention was designed to promote heart health through interactive exercises and promoting healthy lifestyle choices.

\section{Objectives}

Twenty-five promotoras were trained in the curriculum; they in turn reached 750 Latino participants through community workshops. In order to reach Latinos in both urban and rural settings, we focused on both rural (Kern County) and urban (Los Angeles) communities in Southern California.

\section{Methods}

A community-engaged research approach was taken as it involved the collaboration of a research institution and a community-based organization. Promotoras obtained human subjects certification, were trained on research protocols, obtained informed consent, collected de-identified pre and post data from community participants, and contributed to data interpretation as community advisory board members.

\section{Results}

Compared to baseline, 3-month follow-up data indicate community participants made significant changes

\footnotetext{
* Correspondence: kkubicek@chla.usc.edu

'Community Engagement Program, Southern California Clinical and

Translational Science Institute, University of Southern California, Los Angeles,

CA, 90089, USA

Full list of author information is available at the end of the article
}

in: 1) the amount of physical activity performed ( $<<$ $0.001)$; 2) consumption of fruits and vegetables ( $\mathrm{p}<$ 0.001 ); and 4) the proportion who implemented lifestyle changes in their households to decrease their risk for cardiovascular disease $(\mathrm{p}<0.001)$.

\section{Discussion}

This project adds to the evidence-base that promotoras can be important players in the field of dissemination and implementation science while also ensuring cultural competency - important when considering health disparities. As trusted and known members of the community, protmotoras can effectively recruit and retain community members into evidence-based programs. Also, promotoras can be active partners in research with appropriate training and supervision. A 12-month follow-up with community participants is currently underway.

\section{Funding source}

This project was supported through a contract with the Altarum Institute and a grant from the National Institute of Heart, Lung and Blood Institute (GS10F0231K/ HHSN268200900114U).

\footnotetext{
Authors' details

'Community Engagement Program, Southern California Clinical and Translational Science Institute, University of Southern California, Los Angeles, CA, 90089, USA. ${ }^{2}$ Department of Preventive Medicine, Keck School of Medicine, University of Southern California, Los Angeles, CA, 90089, USA. ${ }^{3}$ Vision y Compromiso, Los Angeles, CA, 90012, USA. ${ }^{4}$ Division of Research on Children, Youth and Families, Children's Hospital Los Angeles, Los Angeles, CA, 90027, USA.
} 
doi:10.1186/1748-5908-10-S1-A55

Cite this article as: Kubicek et al:: Promotoras (community health workers) improve heart health among Latinos in rural and urban settings. Implementation Science 2015 10(Suppl 1):A55.

Submit your next manuscript to BioMed Central and take full advantage of:

- Convenient online submission

- Thorough peer review

- No space constraints or color figure charges

- Immediate publication on acceptance

- Inclusion in PubMed, CAS, Scopus and Google Scholar

- Research which is freely available for redistribution 